\title{
Influence of surface finishing and binder phase on friction and wear of WC based hardmetals
}

\author{
K. Bonny ${ }^{1, a}$, P. De Baets ${ }^{1, b}$, O. Van der Biest ${ }^{2, c}$, J. Vleugels ${ }^{2, d}$, B. Lauwers ${ }^{3, e}$ \\ ${ }^{1}$ Ghent University (UGent), Dep. Mechanical Construction \& Production, IR04, Belgium \\ ${ }^{2}$ Catholic University Leuven (K.U.Leuven), Dep. Metallurgy \& Materials Engineering, MTM, Belgium \\ ${ }^{3}$ Catholic University Leuven (K.U.Leuven), Dep. Mechanical Engineering, PMA, Belgium \\ akoenraad.bonny@ugent.be, ${ }^{b}$ patrick.debaets@ugent.be, comer.vanderbiest@mtm.kuleuven.be, \\ djozef.vleugels@mtm.kuleuven.be, ${ }^{e}$ bert.lauwers@mech.kuleuven.be
}

Keywords: cemented carbide, wire EDM, dry friction, reciprocating sliding wear, pin on plate.

\begin{abstract}
At present, cobalt is the most commonly used binder material in tungsten carbide based hardmetals. Current research on sliding wear performance of these cemented carbides, however, reveals promising results for nickel binder as well. Test samples of WC-Co and WC-Ni hardmetals have been machined and surface finished by wire-EDM and grinding. From comparative dry sliding pin-on-plate experiments on wire-EDM'ed, ground and polished grades, correlations are derived between wear volume loss and friction on the one hand and contact pressure, sliding distance, binder phase and microstructure on the other hand. The lowest wear levels are encountered with polished cemented carbides. The EDM induced surface modification turns out to deteriorate wear resistance, especially during the running-in stage of sliding. These findings are in agreement with Xray diffraction measurements of the residual stress level in the WC phase.
\end{abstract}

\section{Introduction}

WC based cemented carbides are widely used in engineering applications for their excellent mechanical properties and outstanding wear resistance in combination with high toughness. Even in the domain of aerospace, which requires properties of ultra-hardness, high erosion/frictionresistance and high heat stability, cemented carbides are mostly the preferred choice in terms of cost, lifetime and productivity, despite competition from pure engineering ceramics. The superior properties obtained with cobalt bound materials has made this metal the most commonly used binder. Nickel and iron are applied as well, however, to a much lower extent.

The general effect of surface finishing operations on tribological behavior has already been studied in literature, e.g. [1,2]. For materials with high strength, wear rate is low and the initial surface finish may become important. This is the case for sliding contact between cemented carbides, where plastic deformation is low and the surface texture changes gradually.

This paper investigates the influence of surface finishing operations on the wear behavior of WC$\mathrm{Co}$ and WC-Ni based cemented carbide grades sliding reciprocatively against WC-Co cemented carbide pins. Correlations between the coefficient of friction and the wear resistance on the one hand and binder type and distinctive surface finishing conditions on the other hand were determined.

\section{Experimental}

WC based cemented carbides. The cemented carbides consist of very hard WC grains, cemented in a binder matrix of tough $\mathrm{Co}$ or $\mathrm{Ni}$ by liquid phase sintering. The chemical, physical, mechanical and microstructural properties of the $\mathrm{WC} 10 \mathrm{Co}, \mathrm{WC} 12 \mathrm{Co}(\mathrm{V}), \mathrm{WC} 12 \mathrm{Co}(\mathrm{Cr}), \mathrm{WC} 10 \mathrm{Co}(\mathrm{Cr} / \mathrm{V})$, $\mathrm{WC} 6 \mathrm{Co}(\mathrm{Cr} / \mathrm{V})$ and $\mathrm{WC} 8 \mathrm{Ni}(\mathrm{Cr})$ grades are given elsewhere [3]. They were manufactured by wireEDM (ROBOFIL 2030SI, Charmilles Technologies) or grinding (JF415DS, Jung, Göppingen, Germany) with a diamond grinding wheel (type MD4075B55, Wendt Boart, Brussels, Belgium). 
The wire-EDM process was conducted in demineralised water (dielectric conductivity $5 \mu \mathrm{S} / \mathrm{cm}$ ), using a brass wire (CuZn37) electrode with a diameter of $0.25 \mathrm{~mm}$ and a tensile strength of 500 $\mathrm{MPa}$. Initial rough cutting was carried out with high spark thermal energy to get a higher material removal rate. In order to improve the surface quality, several consecutive finish cuts with globally decreasing energy input and pulse duration were performed. For the dry sliding experiments, one rough (E3) and 3 finish cut (E8, E21, E23) EDM regimes, together with surface grinding and polishing, leading to distinctive surface roughness levels $R_{a}$ and $R_{t}$ (see Table 1), were selected. The generator settings for the mentioned EDM regimes are described elsewhere [4].

Table 1: $R_{a}$ and $R_{t}$ roughness for the rough $(E 3)$ and smoother EDM regimes (E8-E23) and grinding (measured along and perpendicular direction) and polishing of the cemented carbides

\begin{tabular}{|c|c|c|c|c|c|c|c|c|c|c|c|c|}
\hline \multirow{2}{*}{$\begin{array}{l}\text { grade } \\
\text { surface } \\
\text { finish }\end{array}$} & \multicolumn{2}{|c|}{ WC8Ni(Cr) } & \multicolumn{2}{|c|}{ WC10Co } & \multicolumn{2}{|c|}{$\mathrm{WC} 12 \mathrm{Co}(\mathrm{V})$} & \multicolumn{2}{|c|}{ 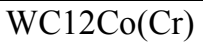 } & \multicolumn{2}{|c|}{$\mathrm{WC} 10 \mathrm{Co}(\mathrm{Cr} / \mathrm{V})$} & \multicolumn{2}{|c|}{$\mathrm{WC6Co}(\mathrm{Cr} / \mathrm{V})$} \\
\hline & $\begin{array}{c}\mathrm{R}_{\mathrm{a}} \\
{[\mu \mathrm{m}]}\end{array}$ & $\begin{array}{c}\mathrm{R}_{\mathrm{t}} \\
{[\mu \mathrm{m}]}\end{array}$ & $\begin{array}{c}\mathrm{R}_{\mathrm{a}} \\
{[\mu \mathrm{m}]}\end{array}$ & $\begin{array}{c}\mathrm{R}_{\mathrm{t}} \\
{[\mu \mathrm{m}]}\end{array}$ & $\begin{array}{c}\mathrm{R}_{\mathrm{a}} \\
{[\mu \mathrm{m}]}\end{array}$ & $\begin{array}{c}\mathrm{R}_{\mathrm{t}} \\
{[\mu \mathrm{m}]}\end{array}$ & $\begin{array}{c}\mathrm{R}_{\mathrm{a}} \\
{[\mu \mathrm{m}]}\end{array}$ & $\begin{array}{c}\mathrm{R}_{\mathrm{t}} \\
{[\mu \mathrm{m}]}\end{array}$ & $\begin{array}{c}\mathrm{R}_{\mathrm{a}} \\
{[\mu \mathrm{m}]}\end{array}$ & $\begin{array}{c}\mathrm{R}_{\mathrm{t}} \\
{[\mu \mathrm{m}]}\end{array}$ & $\begin{array}{c}\mathrm{R}_{\mathrm{a}} \\
{[\mu \mathrm{m}]}\end{array}$ & $\begin{array}{c}\mathrm{R}_{\mathrm{t}} \\
{[\mu \mathrm{m}]}\end{array}$ \\
\hline E3 & 1.89 & 14.37 & 2.08 & 15.18 & 2.31 & 15.84 & 2.37 & 16.08 & 2.34 & 17.36 & 2.08 & 17.02 \\
\hline E8 & 1.14 & 5.545 & 1.07 & 6.62 & 1.3 & 7.1 & 1.29 & 8.67 & 1.2 & 6.8 & 1.00 & 5.95 \\
\hline E21 & 0.24 & 2.24 & 0.24 & 2.16 & 0.26 & 2.38 & 0.24 & 2.99 & 0.24 & 2.73 & 0.37 & 3.05 \\
\hline E23 & 0.14 & 1.85 & 0.15 & 1.02 & 0.18 & 1.04 & 0.16 & 1.02 & 0.17 & 1.08 & 0.24 & 1.29 \\
\hline Grinding $\perp$ & 0.26 & 2.10 & 0.25 & 2.04 & 0.27 & 2.08 & 0.19 & 1.74 & 0.26 & 2.25 & 0.22 & 1.83 \\
\hline Grinding // & 0.14 & 2.09 & 0.08 & 0.56 & 0.09 & 0.68 & 0.09 & 0.67 & 0.22 & 1.83 & 0.09 & 1.95 \\
\hline 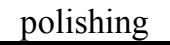 & 0.003 & 0.026 & 0.003 & 0.023 & 0.005 & 0.031 & 0.005 & 0.029 & 0.006 & 0.042 & 0.006 & 0.044 \\
\hline
\end{tabular}

Wear testing. The sliding wear behavior of wire-EDM'ed WC-Co cemented carbides was evaluated using a high frequency tribometer, in which a $\mathrm{WC} 6 \mathrm{Co}(\mathrm{Cr} / \mathrm{V})$ cemented carbide pin was reciprocally slid against WC-Co and WC-Ni cemented carbide counter plates, in conformity with ASTM G133. The tip of the pins was a hemisphere, with average rounding radius and roughness parameters $R_{a}$ and $R_{t}$ of $4.08 \mathrm{~mm}, 0.35 \mu \mathrm{m}$ and $2.68 \mu \mathrm{m}$ respectively.

Contact loads were varied from $15 \mathrm{~N}$ up to $35 \mathrm{~N}$. The stroke length of the oscillating motion was $15 \mathrm{~mm}$. A sliding velocity of $0.3 \mathrm{~m} / \mathrm{s}$ was applied. The test duration was associated with a sliding distance of $10 \mathrm{~km}$, allowing post-mortem wear volumes to be compared. Before each test, the specimens were cleaned ultrasonically with acetone. The wear topography was quantified using surface scanning equipment (Somicronic ${ }^{\circledR}$ EMS Surfascan 3D, type SM3, needle type ST305). The wear scars were examined by scanning electron microscopy (SEM, XL-30 FEG, FEI, The Netherlands), equipped with an energy dispersion X-ray spectroscopy system (EDS).

\section{Results and discussion}

Friction and wear depth. The applied normal force $\left(\mathrm{F}_{\mathrm{N}}\right)$ and the concomitant tangential friction force $\left(\mathrm{F}_{\mathrm{T}}\right)$ were recorded continuously, by means of a load-cell and a piezoelectric transducer respectively. The $\mathrm{F}_{\mathrm{T}} / \mathrm{F}_{\mathrm{N}}$ forces ratio is defined as the coefficient of friction $(\mu)$, which can be differentiated in a static $\left(\mu_{\text {stat }}\right)$ and a dynamic $\left(\mu_{\text {dyn }}\right)$ component. At the same time, wear depth curves, resulting from the pin penetrating the counter plate sample, were acquired by an inductive displacement transducer. Results of real-time monitoring of friction and combined wear depth for $\mathrm{WC} 12 \mathrm{Co}(\mathrm{Cr})$ flat/ $\mathrm{WC} 6 \mathrm{Co}(\mathrm{Cr} / \mathrm{V})$ pin combinations as function of sliding distance, as well as post mortem wear volumes and volumetric wear rates, i.e., integrated wear volume obtained by surface profilometry, and coefficients of friction, for WC-Co and WC-Ni grades, after a $10 \mathrm{~km}$ sliding wear path, as function of the applied contact load, are compared in Fig. 1. Each curve is an average of at least two wear experiments performed under identical conditions, with a standard deviation of less than $10 \%$ between different samples of the same material. The error bars indicating the extent of the variations are excluded to make the figure better readable.

The static and dynamic component of the friction coefficient are found to vary similarly as function of the sliding distance, however at a different level, Fig. 1(a). The coefficient of friction and wear depth are noticed to increase abruptly during the first sliding metres and, after a running-in 
stage, reach a steady state regime, in which the wear depth and wear rate vary exponentially as function of the sliding wear path, Fig. 1(b). The effect of the wire-EDM process and the distinctive EDM-regimes on friction and wear is quite pronounced. The lowest friction and wear level is encountered with the polished cemented carbide samples, whereas the rough EDM cut specimens exhibit the highest friction and wear. Moreover, both friction and wear are noticed to decrease with finer-executed EDM, up to values nearby to those recorded for the equivalent ground cemented carbide grades. The differences in friction level between wire-EDM'ed, ground and polished samples are noticed to diminish with increasing sliding wear path length.

Rising contact load is noticed to decrease the friction coefficient and wear rate, but increases the wear volume, Fig. 1(c,d). Moreover, the highest wear level appears with the lowest hardness grade, i.e. $\mathrm{WC10Co}$, whereas the highest wear resistance appears for the $\mathrm{WC} 8 \mathrm{Ni}(\mathrm{Cr})$ grade.

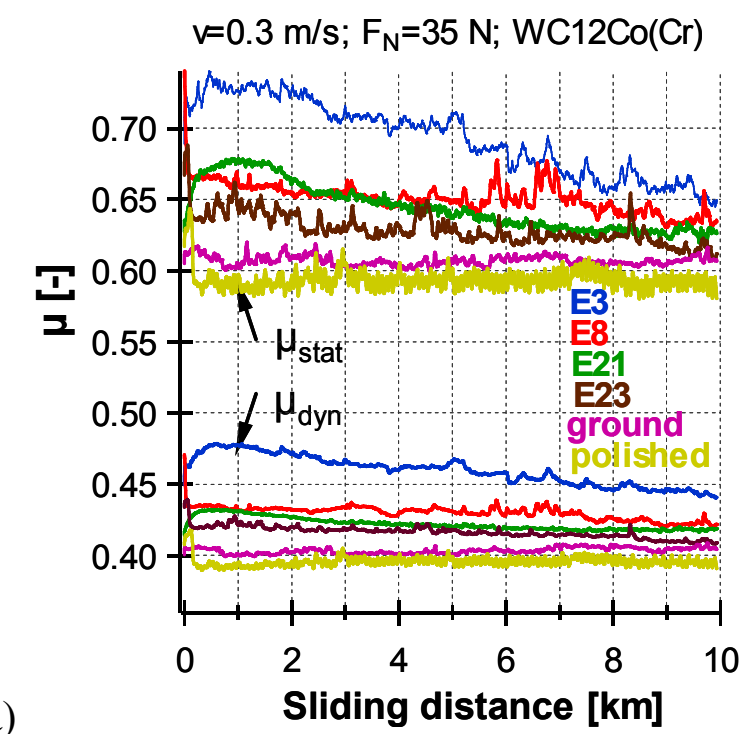

(a) Sliding distance $[\mathrm{km}]$

(b)
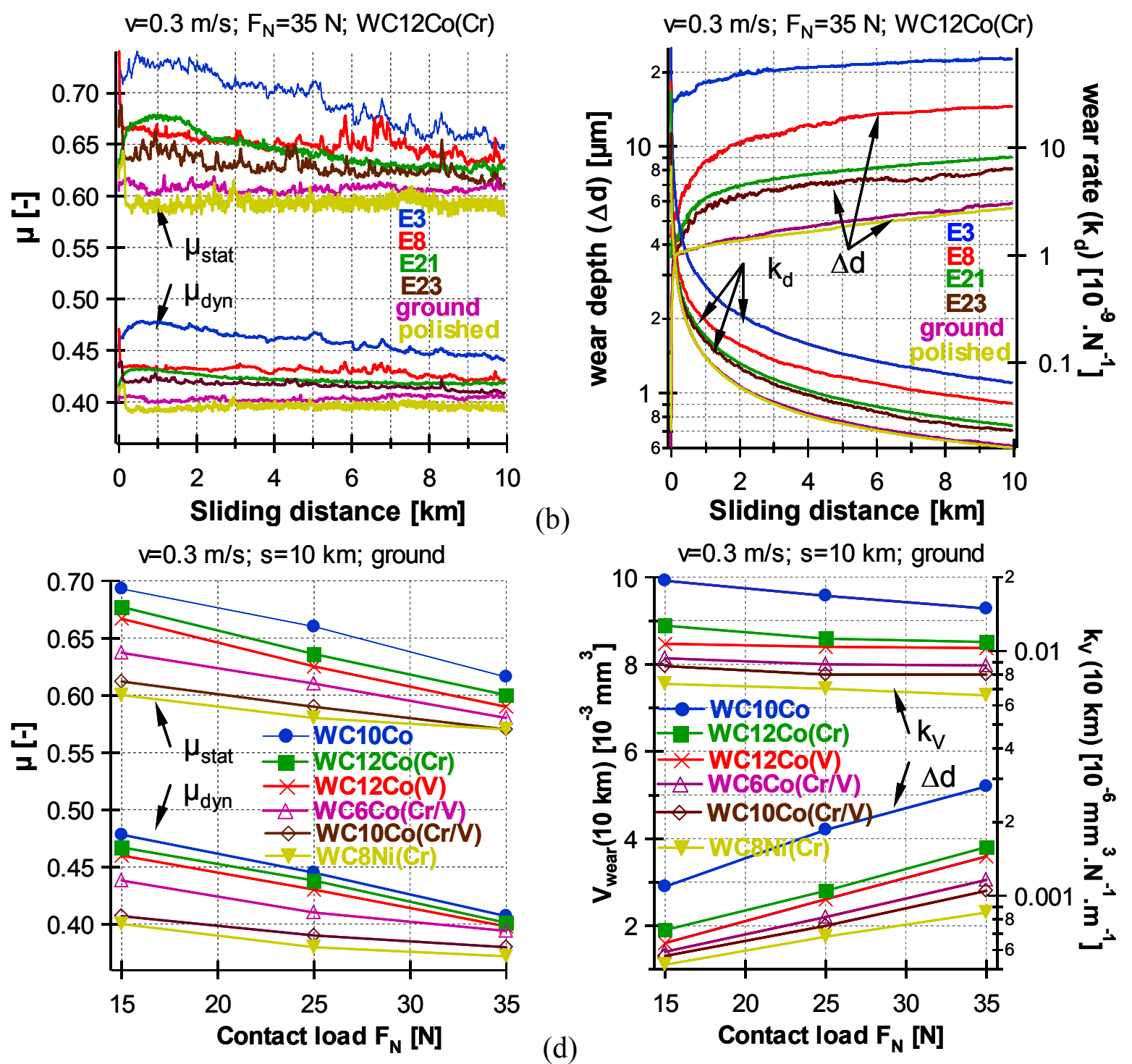

(c)

(d)

Fig. 1. static and dynamic friction coefficient (left) and wear depth and wear rate (right) as function of sliding distance (a,b) and contact load (c,d) for WC-Co or WC-Ni flat/ WC-Co pin pairs

Wear surface analysis. SEM-investigation on the wear scars of WC-Co and WC-Ni cemented carbides allowed to identify the main wear mechanisms as abrasion, microcracking, grain fracture, grain pull out and surface binder removal, Fig. 2. The higher wear damage for wire-EDM'ed surfaces could be associated with more pronounced occurrence of these wear mechanisms due to the recast layer induced by EDM $[5,6]$. Within the range of applied surface finishing conditions, the optical appearance of all wear tracks was smooth, indicating that the surface of the cemented carbides was polished as a result of the sliding contact with the pin. The softer binder phase turns 
out to be removed preferably from the top layer of the WC grains, making them more prone to breaking out from the surface. Furthermore, high contact loads are found to completely remove the wire-EDM induced recast layer in WC-Co, contrary to the WC8Ni(Cr) cemented carbide, Fig. 2(b).

(a)
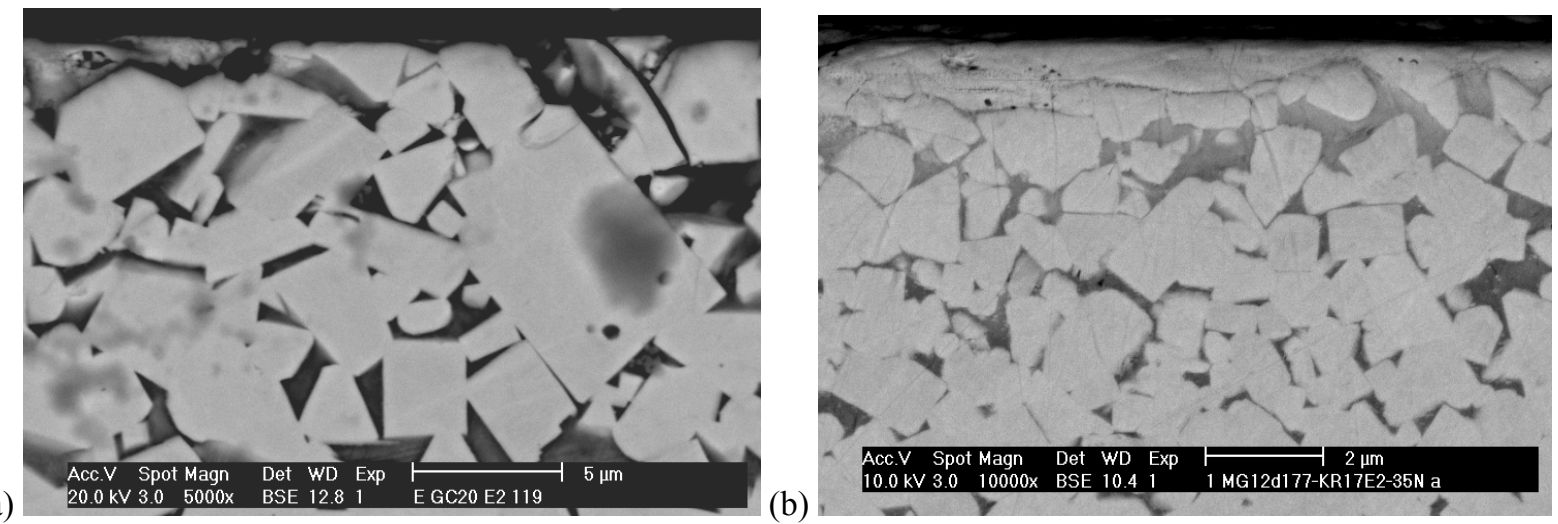

Fig. 2. SEM cross-sectioned views in the central wear tracks of wire-EDM'ed (a) WC12Co(V) and (b) WC8Ni(Cr), after sliding $10 \mathrm{~km}$ at $0.3 \mathrm{~m} / \mathrm{s}$ under a $35 \mathrm{~N}$ contact load

\section{Conclusions}

Comparative dry sliding tests of polished, ground and electro-eroded WC-Co and WC-Ni cemented carbides against WC-Co pins, revealed several mechanisms involved in their global wear process: cracking, fracture, pull out or polishing of WC grains, surface binder removal and abrasion. Rising contact load increases the wear volume but decreases wear rate and friction coefficient. Wire-EDM was found to deteriorate the wear resistance, due to a thermally affected top layer and concomitant binder modification, residual tensile surface stresses and higher surface roughness. However, consecutive execution of gradually finer EDM finishes reduces the wear rate significantly nearby to that of ground cemented carbides. The most favorable tribological results were obtained for polished samples and the WC-Ni grade, emphasizing the importance of further investigation in this direction.

\section{Acknowledgements}

This research was co-financed by the Flemish Institute for the promotion of Innovation by Science and Technology in industry (IWT). The authors gratefully recognize the support and scientific contributions from the Ghent University (UGent) and the Catholic Leuven University (K.U.Leuven). Special appreciation goes to CERATIZIT for supplying the cemented carbide grades.

\section{References}

[1] G. A. Garzino-Demo and F. L. Lama, The effect of surface finish of matching materials on friction and wear of uncoated and unlubricated sliding bodies, Surface and Coatings Technology, Vol. 86-87, Part 2 (1996), 603-609

[2] M. L. Jeswani, Roughness and wear characteristics of spark-eroded surfaces, Wear, Vol. 51 (1978), 227-236

[3] K. Bonny, P. De Baets, B. Lauwers, J. Vleugels, O. Van Der Biest, "Influence of electro-discharge machining, microstructural and mechanical properties on wear of hardmetals", Plansee 16th Int. Sem., Vol. 2 (2005), 863-877

[4] K. Bonny, P. De Baets, B. Lauwers, W. Liu, J. Vleugels, S. Salehi, Electrical discharge machinability of WC-Co based cemented carbides and effects on reciprocating sliding friction behavior, submitted to Wear

[5] Jiang, D., Anné, G., Vleugels, J., Vanmeensel, K., Eeraerts, W., Liu, W., Lauwers, B., Van der Biest, O., Residual stress in hardmetals caused by grinding and EDM machining and its influence on flexural strength, Proc. 16th Int. Plansee Seminar, Powder Metallurgical High Performance Materials, Vol. 2 (2005), 1075-1085

[6] Yakou T., Hasegawa T., Relations between condition and electrically discharge machining and depth of surface crack in cemented carbides, Trans. Japan Soc. Mec., Vol. 61 (1995), 1192-1197 